\title{
Electrophysiological Characterization of GABAergic Neurons in the Ventral Tegmental Area
}

\author{
Scott C. Steffensen, ${ }^{1}$ Adena L. Svingos, ${ }^{2}$ Virginia M. Pickel, ${ }^{2}$ and Steven J. Henriksen ${ }^{1}$ \\ ${ }^{1}$ The Scripps Research Institute, La Jolla, California 92037, and '2Cornell University Medical College, \\ New York, New York 10021
}

\begin{abstract}
GABAergic neurons in the ventral tegmental area (VTA) play a primary role in local inhibition of mesocorticolimbic dopamine (DA) neurons but are not physiologically or anatomically well characterized. We used in vivo extracellular and intracellular recordings in the rat VTA to identify a homogeneous population of neurons that were distinguished from DA neurons by their rapid-firing, nonbursting activity $(19.1 \pm 1.4 \mathrm{~Hz})$, short-duration action potentials (310 $\pm 10 \mu \mathrm{sec})$, EPSP-dependent spontaneous spikes, and lack of spike accommodation to depolarizing current pulses. These non-DA neurons were activated both antidromically and orthodromically by stimulation of the internal capsule (IC; conduction velocity, $2.4 \pm 0.2 \mathrm{~m} / \mathrm{sec}$; refractory period, $0.6 \pm 0.1 \mathrm{msec}$ ) and were inhibited by stimulation of the nucleus accumbens septi (NAcc). Their firing rate was moderately reduced, and their IC-driven activity was suppressed by microelectrophoretic application or systemic administration of NMDA receptor antagonists. VTA non-DA neurons were re-
\end{abstract}

The mesolimbic dopamine (DA) pathway originating in the ventral tegmental area (VTA) and projecting to the nucleus accumbens septi (NAcc) is considered to be a fundamental component in the neural system underlying natural rewarding behaviors and the reinforcing properties of drugs of abuse, including the psychostimulants, opioids, and alcohol (Wise, 1996; Koob and Le Moal, 1997). Neurochemical lesions of the VTA produce deficits in exploratory behavior, locomotor activity, and measures of cognitive function (Le Moal et al., 1969, 1975; Simon et al., 1979, 1980). It has been suggested that these deficits may result from abnormal regulation of the electrical activity of midbrain DA neurons (Kalivas and Duffy, 1993).

The anatomical projections of DA neurons in the substantia nigra pars compacta (SNc; nucleus A9) and adjacent VTA (nucleus A10) have been carefully examined (Fallon and Moore, 1978; Beckstead et al., 1979; Swanson, 1982). Dopamine neurons in the midbrain have been identified by tyrosine hydroxylase (TH) immunoreactivity and by certain electrophysiological and pharmacological characteristics, including (1) long-duration (2-5 msec), biphasic or triphasic action potentials, (2) a low rate (2-9

Received April 27, 1998; revised July 10, 1998; accepted July 16, 1998.

This work was supported by Public Health Service Grants AA10075 to S.C.S., DA08301 to S.J.H., and DA04600 and MH40342 to V.M.P. and by an Aaron Diamond postdoctoral fellowship to A.L.S. We thank Dr. Antonieta Lavin for invaluable training with intracellular recordings in vivo and Eric Colago for histological assistance.

Correspondence should be addressed to Dr. Scott C. Steffensen, Department of Neuropharmacology (CVN-13), The Scripps Research Institute, 10550 North Torrey Pines Road, La Jolla, CA 92037.

Copyright (C) 1998 Society for Neuroscience $\quad 0270-6474 / 98 / 188003-13 \$ 05.00 / 0$ corded intracellularly and showed relatively depolarized resting membrane potentials $(-61.9 \pm 1.8 \mathrm{mV})$ and small action potentials $(68.3 \pm 2.1 \mathrm{mV})$. They were injected with neurobiotin and shown by light microscopic immunocytochemistry to be multipolar cells and by electron microscopy to contain GABA but not the catecholamine-synthesizing enzyme tyrosine hydroxylase (TH). Neurobiotin-filled dendrites containing GABA received asymmetric excitatory-type synapses from unlabeled terminals and symmetric synapses from terminals that also contained GABA. These findings indicate that VTA non-DA neurons are GABAergic, project to the cortex, and are controlled, in part, by a physiologically relevant NMDA receptormediated input from cortical structures and by GABAergic inhibition.

Key words: ventral tegmental area; nondopamine; intracellular; immunocytochemistry; GABA; neurobiotin; refractory period; superexcitability

impulses/sec) of spontaneous activity marked by bursting episodes characterized by spike-amplitude decrement, (3) relatively slow axonal conduction velocity $(\sim 0.5 \mathrm{~m} / \mathrm{sec})$, (4) inhibition of spontaneous activity by DA receptor agonists and subsequent reversal by DA receptor antagonists (Wang, 1981a,b; Grace and Bunney, 1983; Chiodo, 1988), and (5) a marked inward rectification in response to an applied hyperpolarizing current (Grace and Onn, 1989; Lacey et al., 1989).

In the VTA, neurons without detectable TH immunoreactivity lie in close proximity to TH-labeled cells and are presumed to be GABAergic neurons (Nagai et al., 1983; Otterson and StormMathisen, 1984; Mugnaini and Oertel, 1985). Neurons having nondopaminergic physiological properties have also been identified in this region. These properties include (1) relatively high rates of spontaneous activity ( $>10$ impulses/sec), (2) action potential durations of $<1 \mathrm{msec}$, and (3) lack of the inward rectification after-hyperpolarizing current (Grace and Onn, 1989; Lacey et al., 1989). These neurons appear to represent a heterogeneous population whose neurochemical identity, projections, innervation, and physiological significance are less clear than that of DA neurons in the VTA.

Current evidence supports the contention that non-DA neurons play a significant role in the regulation of DA neurons in the VTA. Thus, the neurochemical, electrophysiological, and hodological characterization of VTA non-DA neurons is essential to an understanding of the reinforcing and rewarding properties of drugs of abuse as well as the natural rewarding behaviors ascribed to DA neurons (Wise et al., 1992; Wise, 1996). Thus, we sought to identify the physiological properties, transmitter content, and 
synaptic connectivity of a homogeneous population of non-DA neurons in the VTA. Physiologically characterized neurons were filled with neurobiotin and processed for electron microscopic immunocytochemical labeling of GABA or TH to test specifically the hypothesis that the identified neurons were GABAergic.

\section{MATERIALS AND METHODS}

\section{Subjects and surgical preparation}

Male Sprague Dawley rats (250-350 gm) were anesthetized with halothane $(3.0-4.0 \%)$ and placed into a stereotaxic apparatus. Body temperature was monitored and maintained at $37.0 \pm 0.1^{\circ} \mathrm{C}$ by a feedbackregulated heating pad. The skull was exposed, and holes were drilled to accommodate placement of stimulating and recording electrodes. The dura was opened over recording sites to prevent breakage of micropipettes. Halothane anesthesia was maintained at $0.75 \%$ after surgery.

\section{Extracellular recordings}

Extracellular potentials were recorded by a single $3.0 \mathrm{M} \mathrm{NaCl-filled}$ micropipette [5-10 M $\Omega$; inner diameter (i.d.), 1-2 $\mu \mathrm{m}$ ] cemented $20-40$ $\mu \mathrm{m}$ distal to a seven-barrel micropipette (30-80 $\mathrm{M} \Omega$ barrels) and amplified with an Axon Instruments Axoprobe-1A microelectrode amplifier/ headstage. Microelectrode assemblies were oriented, via stereotaxic coordinates, into the VTA (from bregma: $5.6-6.0 \mathrm{~mm}$ posterior; $0.5-1.0$ $\mathrm{mm}$ lateral; and $7.0-8.5 \mathrm{~mm}$ ventral) with a Burleigh piezoelectric microdrive. Single-unit activity was filtered at $1-3 \mathrm{kHz}(-3 \mathrm{~dB})$ for "filtered" recordings and at $0.1-10 \mathrm{kHz}$ for "unfiltered" recordings. The potentials were displayed on analog and digital oscilloscopes. Squarewave constant-current pulses $(50-1000 \mu \mathrm{A} ; 0.15 \mathrm{msec}$ duration; average frequency, $0.1 \mathrm{~Hz}$ ) were generated by a Grass PSIU6 isolation unit controlled by a MASTER-8 Pulse Generator or by computer. The internal capsule (IC) (from bregma: $-2.5 \mathrm{~mm}$ posterior; $2.5-3.0 \mathrm{~mm}$ lateral; and $6.0-7.0 \mathrm{~mm}$ ventral) and NAcc (from bregma: $+1.5 \mathrm{~mm}$ anterior; $1.4 \mathrm{~mm}$ lateral; and $5.5-7 \mathrm{~mm}$ ventral) were stimulated with insulated, bipolar stainless steel electrodes.

\section{Single-unit activity}

We evaluated spikes that had a $>5: 1$ signal-to-noise ratio. Extracellularly recorded action potentials were discriminated with Mentor N-750 or Fintronics spike analyzers and converted to TTL-level pulses. Single-unit potentials, discriminated spikes, and stimulation events were captured by National Instruments NB-MIO-16 A/D digital input/output, and counter/timer data acquisition boards in Macintosh-type computers. Potentials were digitized at $20 \mathrm{kHz}$ and 12-bit voltage resolution.

\section{Analysis of responses}

Waveforms, discriminated spikes, and stimulation events were processed with National Instruments LabVIEW software. Interspike-interval or peristimulus spike histograms were constructed for determinations of firing rate and single-unit modal (e.g., bursting vs nonbursting) activity. The histograms were normalized to the number of spikes before and after drug or experimental treatment (1 sec epoch; 2000 spikes; 2 msec bin width). A cell was considered to be bursting if its pattern of discharge was characterized by multiple action potentials over a short time period $(10-15 \mathrm{msec})$ with spike-amplitude decrement and spike-interval increment. For determinations of the probability of the occurrence of a driven spike across stimulus levels, peristimulus spike histograms were generated at $0.5 \mathrm{~Hz}$ stimulation and averaged over 40 trials $( \pm 100 \mathrm{msec}$ window; 2 msec bin width). The number of driven spikes at each stimulus level was determined by rectangular integration using IGOR Pro software.

Spike duration was determined by measuring the time between halfpeak amplitude for the falling and rising edges of the unfiltered extracellular spike. The criteria for antidromicity were (1) the lack of an EPSP preceding the spike (seen best in intracellular recordings), (2) nearconstant latency at threshold stimulus levels, (3) faithful following of five pulses at $200 \mathrm{~Hz}$, and, most importantly, (4) collision between spontaneously occurring and IC-evoked spikes. Collision tests were performed by triggering the stimulator with an unfiltered spontaneous spike and by adjusting the spontaneous-spike to driven-spike interval such that stimulation of the axon of the cell failed to produce a spike that reached the somatic recording electrode. The absolute refractory period $r$ of VTA non-DA neurons was calculated by the following formula: $r=I-2 L$, where $I$ is the interval from the ogive of the spontaneous spike (the fastest falling edge; usually approximately one-half of the peak amplitude of the spike) to the ogive of the driven spike and $L$ is the latency from the stimulus artifact to the ogive of the driven spike. We accomplished this by setting $I$ at $2 L$, where $100 \%$ extinction of the driven spike was evident at twice the threshold stimulus level, and by increasing $I$ in $0.2 \mathrm{msec}$ increments until a driven spike occurred.

\section{Histology}

After recording, cell locations were labeled by electrophoretic application of pontamine sky blue $2 \%$ (alternating $\pm 10 \mu \mathrm{A}$ current) in $3 \mathrm{M}$ $\mathrm{NaCl}$. After the experimental procedures, the animals were killed with a lethal dose of halothane anesthesia (5\%), and the brains were removed and preserved in $10 \%$ formalin. Histological inspection of the dye injection was accomplished by microscopic inspection of $50 \mu \mathrm{m}$ cryostatsectioned slices. The location of the IC and NAcc stimulation sites was determined by passing $\pm 3.0 \mathrm{~mA}$ current through the bipolar stimulating electrode for $5 \mathrm{sec}$ each and by examination of the lesion site by microscopic inspection of $50 \mu \mathrm{m}$ cryostat-sectioned tissue slices with the aid of potassium ferri/ferrocyanide staining. The results for control and drug treatment groups were derived from calculations performed on the driven and spontaneous activity and were expressed as mean \pm SEM. The results were compared before and after drug treatment by use of the two-tailed $t$ test, at each point.

\section{Drug preparation and delivery}

For in situ microelectrophoretic application in the VTA, we dissolved D,L-2-aminophosphonovalerate (APV; $20 \mathrm{~mm}$; Research Biochemicals, Natick, MA) in $0.9 \%$ saline, loaded the solution into seven-barrel glass micropipettes (barrel i.d., 0.5-1.0 $\mu \mathrm{m}$ ), and microelectrophoretically administered it by current injection $(25-50 \mathrm{nA})$ through the micropipettes.

\section{Intracellular recordings and dye labeling}

For intracellular recordings, VTA non-DA neurons were impaled with sharp micropipettes $(1.0 \mathrm{~mm}$ outer diameter, WPI borosilicate capillary tubing with filament) that were pulled on a vertical pipette puller and filled with $4 \%$ neurobiotin and $1.0 \mathrm{M}$ filtered $(0.22 \mu \mathrm{m}$ Millipore filter; Bedford, MA) potassium acetate (impedance, $50-70 \mathrm{M} \Omega$ ). The animals were prepared in a manner similar to that used for extracellular recording; however, halothane anesthesia was increased to $1 \%$ from $0.75 \%$ to mitigate movement artifacts. The electrodes were lowered to $6500 \mu \mathrm{m}$ below the brain surface and subsequently advanced at 3-5 $\mu \mathrm{m}$ steps while monitoring bridge balance and direct current potential with an Axon Instruments Axoprobe-1A microelectrode amplifier. The bridge was balanced and monitored by capacitance neutralization with $0.5 \mathrm{~Hz}, 20 \mathrm{msec}$ duration, $-0.5 \mathrm{nA}$ current pulses. After electrode impedance changes of $\sim 20 \mathrm{M} \Omega$, as indicated by a negative deflection during the current pulse, the electrode was "buzzed" with high-frequency current and concomitantly advanced 3-5 $\mu \mathrm{m}$ until impalement. Because of the high spontaneous firing of VTA non-DA neurons, extracellularly recorded spikes were usually evident. Impaled neurons often evinced a quiescent period after impalement with recovery to full spike amplitude (usually 60-80 $\mathrm{mV}$ ) and resting potential (usually -55 to $-60 \mathrm{mV}$ ) within $2-5 \mathrm{~min}$. To aid in the recovery, we temporarily used -0.5 to $-1.0 \mathrm{nA}$ constant hyperpolarizing current. Spike accommodation was studied at depolarizing levels up to $+4.0 \mathrm{nA}$. After electrophysiological characterization, impaled neurons were labeled with neurobiotin by passing depolarizing current (+1.0-1.5 nA; $33 \mathrm{~Hz} ; 20 \mathrm{msec}$ duration) for 10-20 min.

\section{Immunocytochemical methods}

Antisera. For the detection of GABA immunoreactivity, a rat antiserum was used that was raised against GABA conjugates and that has been well characterized and published extensively (Bayer and Pickel, 1991). To confirm the selective labeling of GABAergic neurons, we used a highly specific monoclonal TH antibody produced in mice (Incstar, Stillwater, $\mathrm{MN}$ ) for the immunolabeling of DA neurons.

Tissue fixation and immunocytochemistry. Rats were killed with an overdose of halothane $(5 \%)$ and rapidly perfused transcardially in the following order: (1) $3 \mathrm{ml}$ of heparinized saline, (2) $60 \mathrm{ml}$ of $3.75 \%$ acrolein in $2 \%$ paraformaldehyde in $0.1 \mathrm{~m}$ phosphate buffer (PB), $\mathrm{pH} 7.4$, and (3) $120-240 \mathrm{ml}$ of $2 \%$ paraformaldehyde in PB. The brains were removed from the cranium and post-fixed in $2 \%$ paraformaldehyde in PB. Perfused brains were cut through the VTA, according to the corresponding plates from the Paxinos and Watson rat brain atlas (1986), into 30-40 $\mu \mathrm{m}$ coronal sections on a Lancer Vibratome. Tissue sections were 


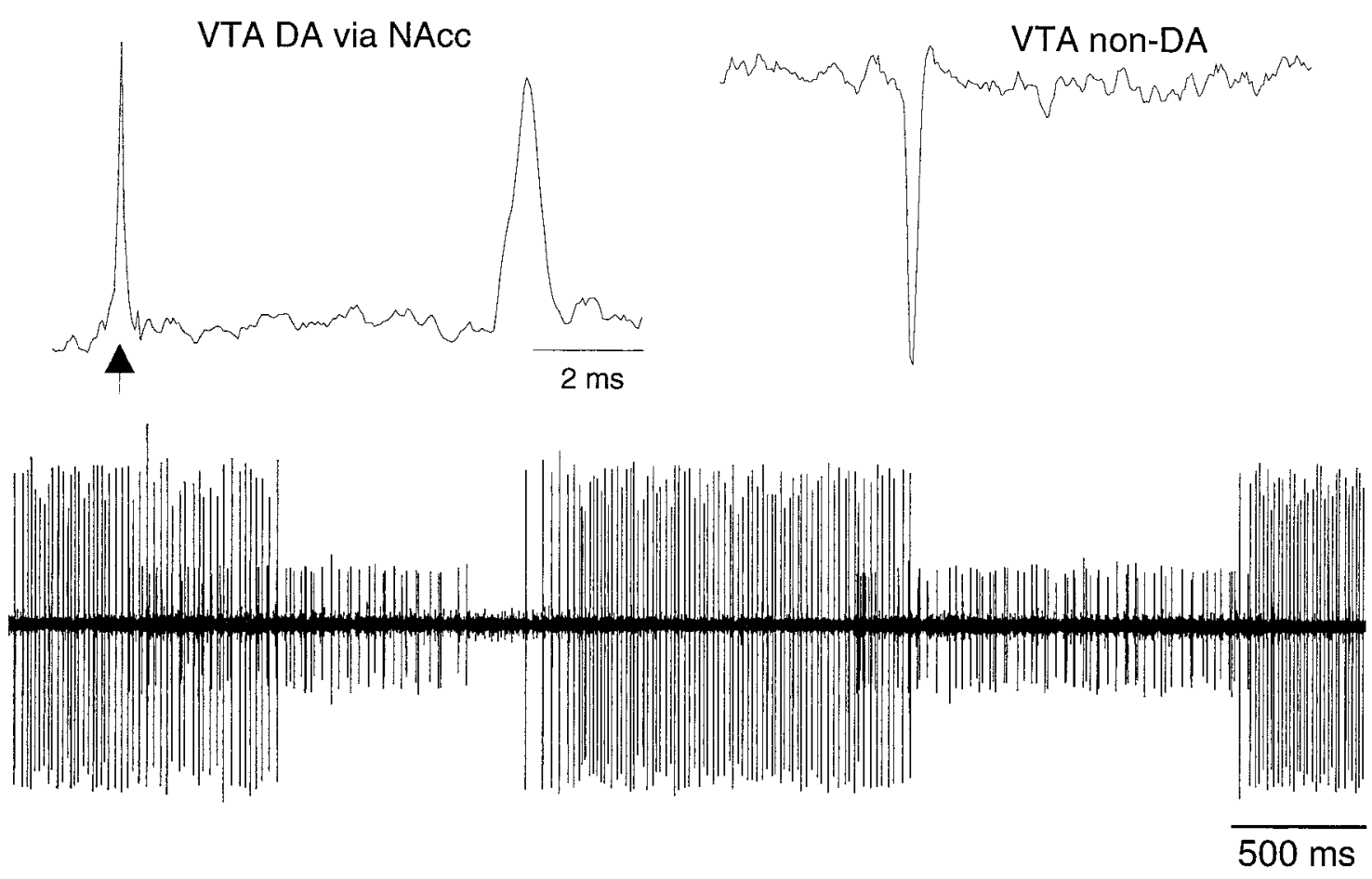

Figure 1. Extracellular electrophysiological characterization of dopamine and nondopamine neurons in the ventral tegmental area. Top, Unfiltered recordings of a VTA DA neuron evoked by stimulation of the NAcc (left) and of a spontaneous non-DA neuron (right) are shown. Calibration bar applies to both. VTA DA neurons were slow-firing $(<1 \mathrm{~Hz})$, bursting neurons that were driven by NAcc stimulation with spike durations of $>500 \mu$ sec $($ arrow indicates NAcc stimulus artifact). VTA non-DA neurons were relatively fast-firing, nonbursting cells that evinced negative-going spikes and were characterized by spike durations of $<500 \mu \mathrm{sec}$. VTA non-DA neurons were not driven by NAcc stimulation. Bottom, Under halothane anesthesia, VTA non-DA neurons evinced pronounced and persistent phasic activity as demonstrated by the two simultaneously recorded VTA non-DA neurons in the filtered trace.

incubated in $1 \%$ sodium borohydride in $0.1 \mathrm{M} \mathrm{PB}$ for $30 \mathrm{~min}$ to bind to active aldehydes. To enhance antibody penetration, we incubated tissue sections in a cryoprotectant solution $(25 \%$ sucrose and $3.5 \%$ glycerol in $0.05 \mathrm{M} \mathrm{PB}$ ) and then freeze-thawed the sections successively in (1) Freon, (2) liquid nitrogen, and (3) room temperature PB. To reduce background labeling, we incubated sections in $0.5 \%$ bovine serum albumin (BSA) in $0.1 \mathrm{~m}$ Tris-buffered saline (TBS) for $30 \mathrm{~min}$. After tissue sections were freeze-thawed, they were rinsed several times in TBS and incubated overnight at room temperature in an ABC/TBS solution (Hsu et al., 1981).

After several rinses in TBS, tissue sections were incubated in a solution of 3,3'-diaminobenzidine (DAB; $22 \mathrm{mg}$ per $100 \mathrm{ml}$ of TBS) and $0.01 \% \mathrm{H}_{2} \mathrm{O}_{2}$ for $6 \mathrm{~min}$ to visualize the neurobiotin. Tissue sections were analyzed by light microscopy for the presence of a filled cell and its processes. Filled cells usually were contained within four to six tissue sections. Tissue sections containing filled cells were separated into those to be processed for light microscopy and those to be processed for dual labeling with either GABA or TH. Tissues processed for light microscopy were rinsed in $0.05 \mathrm{M} \mathrm{PB}$, mounted on gelatin-coated slides, dehydrated via a series of graded ethanols, and coverslipped. Tissue sections were examined using a Nikon light microscope equipped with differential interference contrast optics.

We incubated tissue sections processed for dual-labeling electron microscopy in either rat anti-GABA $(1: 1000)$ or mouse anti-TH $(1: 1000)$ in a solution of $0.1 \% \mathrm{BSA}$ in TBS overnight at $4^{\circ} \mathrm{C}$. We then rinsed them in TBS and incubated them for $3 \mathrm{hr}$ in either anti-rat or anti-mouse colloidal gold-labeled $1 \mathrm{~nm}$ secondary $\operatorname{IgG}(1: 50)$ for detection of GABA or $\mathrm{TH}$, respectively. The sections were then incubated in $2 \%$ glutaraldehyde and reacted with a silver-intense solution (Amersham, Arlington Heights, IL) for an empirically determined amount of time. Sections were then incubated for $60 \mathrm{~min}$ in $2 \%$ osmium tetroxide in $0.2 \mathrm{M} \mathrm{PB}$, dehydrated in a series of ethanols and propylene oxide, and flatembedded in Epon 812 between two pieces of Aclar plastic. We then sectioned the flat-embedded tissue sections $(40-50 \mathrm{~nm})$ on an LKB ultramicrotome from the outer surface of the plastic/tissue interface using a diamond knife (Diatome, Inc.). Tissue sections were collected on to copper mesh grids, counterstained with lead citrate (Reynolds, 1963) and uranyl acetate, and examined with a Phillips CM-10 electron microscope.

Data analysis. We analyzed sections cut from the region of interest based on the maximal labeling of antigens and the morphological quality of the tissue. A Dage video camera and associated software were used to obtain images of the regions to be sectioned for electron microscopy. We used at least 10 grids, containing 2-10 thin sections that had been collected from all vibratome sections. All electron micrographs were taken from the tissue-Epon surface. Fields containing labeling for the antigens were categorized according to the following criteria (Peters et al., 1991): (1) profile type (i.e., somata, dendrites, axons, or glia), (2) subcellular associations (i.e., plasma membranes, smooth endoplasmic reticulum, etc.), (3) types of synaptic contacts (asymmetric, excitatory type and symmetric, inhibitory type) (Carlin et al., 1980), and (4) association between differentially labeled profiles (i.e., colocalization, apposition, etc.). To test the specificity of the immunocytochemical methods, we replaced the primary antiserum with preimmune or normal serum. These controls do not definitively preclude cross-reactivity with other proteins; therefore we refer to "like-reactivity" because of this possibility.

\section{RESULTS}

\section{Extracellular electrophysiological characterization of VTA nondopamine neurons}

VTA non-DA neurons recorded extracellularly in halothaneanesthetized rats were distinguished from VTA DA neurons by location, spontaneous activity, axonal conduction velocity, refractory period, and orthodromic-driven activity. The most distinguishing feature of VTA non-DA neurons was their fast spontaneous activity $(19.1 \pm 1.4 \mathrm{~Hz} ; n=122)$ relative to DA neurons and their uninterrupted phasic activity characterized by alternating $0.5-2 \mathrm{sec} \mathrm{ON}$ and $0.5-2.0 \mathrm{sec}$ OFF periods (mean period, 

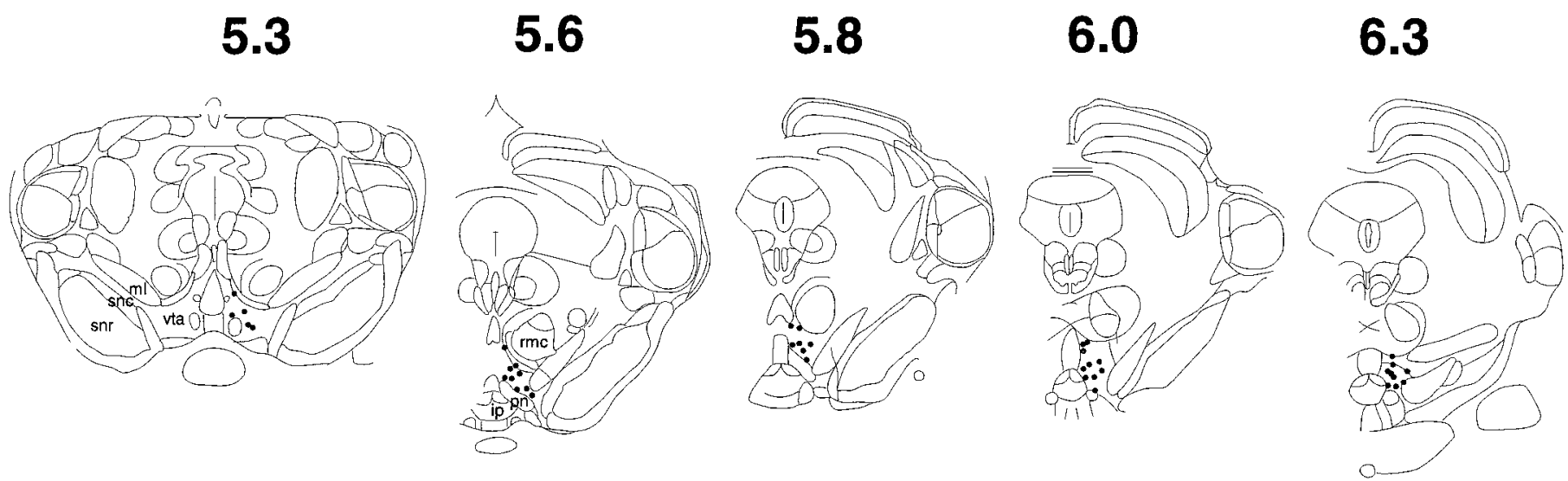

Figure 2. Recording sites of VTA nondopamine neurons. The neuropil surrounding extracellularly recorded VTA non-DA neurons was stained with pontamine sky blue after electrophysiological evaluation. VTA non-DA neurons (filled circles) were localized along the rostrocaudal and dorsoventral extent of the VTA [shown here at 5.3, 5.6, 5.8, 6.0, and $6.3 \mathrm{~mm}$ from bregma (Paxinos and Watson, 1986)]; however, they tended to be encountered in clusters from 200 to $1000 \mu \mathrm{m}$ dorsal to DA neurons. ip. Interpeduncular nucleus; $m l$, medial lemniscus; $p n$, paranigral nucleus; $r m c$, red nucleus, magnocellularis; snc, substantia nigra pars compacta; snr, substantia nigra pars reticulata; $v t a$, ventral tegmental area.

$0.43 \pm 0.07 \mathrm{~Hz}$; Fig. 1). No bursting activity, defined as spikeamplitude decrement and spike-interval increment, was observed in any of the VTA non-DA neurons studied. Unfiltered recordings of VTA non-DA neuron spikes revealed biphasic action potentials, characterized by a prominent, initial negative-going component followed by a small positive-going component (Fig. 1, top). The mean duration of the negative-going spike measured at half-maximal amplitude was $310 \pm 10 \mu \mathrm{sec}(n=93)$. VTA non-DA neurons were found in clusters of neurons whose spontaneous activity appeared to be homogeneous. This is demonstrated by the two neurons recorded simultaneously in Figure 1. In this case, although both neurons are phasic, they are not simultaneously phasic. Although simultaneously recorded neurons were often not synchronous, the baseline voltage noise level recorded within a cluster during the ON phase was often twice that of the baseline activity recorded outside a cluster. Up to 10 neurons could often be recorded in one electrode tract, but, typically, the best two neurons per tract and one to two tracts per animal were studied. After extracellular electrophysiological evaluation of the last recorded neuron in each animal, pontamine sky blue was microelectrophoretically applied at the recording site, and the brains were examined for their location. The extracellular recording sites were localized to the VTA and to the borders of adjacent structures according to the Paxinos and Watson stereotaxic atlas (Fig. 2).

\section{Afferents and efferents of VTA nondopamine neurons}

Stimulation of the IC evoked both antidromic and orthodromic VTA non-DA spikes (Fig. 3). Antidromicity was determined by collision studies and by response to high-frequency stimulation. This proved at times to be problematical because of the short latency of activation of VTA non-DA spikes from the IC (2.1 \pm $0.2 \mathrm{msec} ; n=23$ ) and their high spontaneous firing rate. In the example depicted in Figure $3 A$, IC stimulation evoked a VTA non-DA spike (unfiltered recording) with short latency. The IC-driven spike was extinguished by a preceding spontaneous spike that occurred at a spontaneous-spike to driven-spike interval that was less than double the latency of the evoked spike (Fig. $3 B$ ). If we assume a linear path from the stimulating to the recording electrode, the conduction velocity for VTA non-DA spikes driven antidromically from the IC was $2.4 \pm 0.2 \mathrm{~m} / \mathrm{sec}(n=$ $23)$. The refractory period was $0.6 \pm 0.1 \mathrm{msec}(n=15)$ as determined by collision test (see Materials and Methods). Stimulation of the IC elicited orthodromic spikes in most VTA non-DA neurons with a mean latency of $3.2 \pm 0.3 \operatorname{msec}(n=72)$ in which no collision occurred. Paired-pulse analysis of spikes driven from the IC revealed an inhibitory period for orthodromic spikes (filtered recordings) extending from 3 to $20 \mathrm{msec}$ (Fig. 3C; $n=8$ ) and a superexcitable period for antidromic spikes (filtered recordings) also extending from 3 to $20 \mathrm{msec}$ (Fig. $3 D ; n=8$ ).

\section{NMDA receptor-mediated input to VTA non-DA neurons}

Figure $4 A$ shows a strip-chart recording of a representative VTA neuron whose firing rate decreased after in situ microelectrophoretic application of the competitive NMDA receptor antagonist APV. The firing rate of all VTA non-DA neurons was significantly reduced by APV $35.7 \pm 7 \%$ (Fig. $4 A ; p<0.001 ; n=$ 13 ) or by systemic administration of the noncompetitive NMDA antagonist MK-801 $36.5 \pm 6 \%(0.5 \mathrm{mg} / \mathrm{kg} ; p<0.001 ; n=8$; data not shown). The effects of APV were also tested on the activity of VTA neurons driven orthodromically by IC stimulation. APV blocked the occurrence of IC-driven spikes (Fig. 4B). Highfrequency stimulation of the IC evoked multiple spiking of orthodromic VTA non-DA neurons whose number of discharges exceeded the number of stimulation pulses in the train (Fig. 5A). The latency of some driven spikes elicited by high-frequency stimulation often exceeded the typical latency of a single-stimulus spike by two orders of magnitude (i.e., 2-200 msec). Multiple spiking was strongly dependent on frequency because $200 \mathrm{~Hz}$ stimulation evoked discharges whereas 50 and $400 \mathrm{~Hz}$ did not. The number of pulses in the train and the number of trains were held constant at 10 for all frequencies. Systemic administration of the noncompetitive NMDA antagonist MK-801 $(0.5 \mathrm{mg} / \mathrm{kg}) \mathrm{sig}$ nificantly reduced the multiple discharging associated with tetanic stimulation of the IC (Fig. $5 B ; p<0.001 ; n=4)$. Systemic administration of MK-801 $(0.1 \mathrm{mg} / \mathrm{kg})$ reduced multiple discharging at $200 \mathrm{~Hz}$ by $44 \%(p<0.05 ; n=3)$ compared with $78 \%$ with $0.5 \mathrm{mg} / \mathrm{kg} \mathrm{MK}-801$.

\section{Inhibition of VTA non-DA neurons by nucleus accumbens input}

Stimulation of the NAcc produced a consistent inhibition of VTA non-DA spontaneous activity that extended for $75 \pm 11 \mathrm{msec}$ 
VTA non-DA via IC

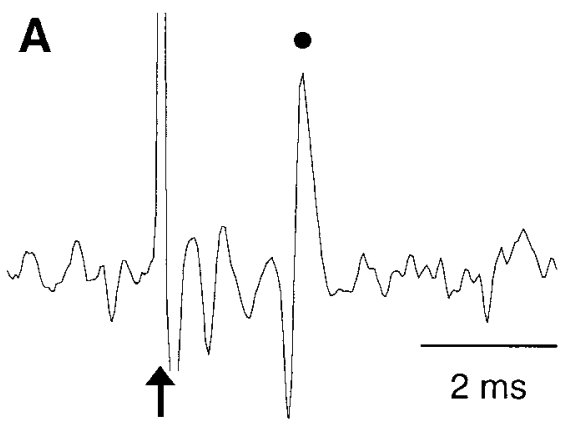

COLLISION

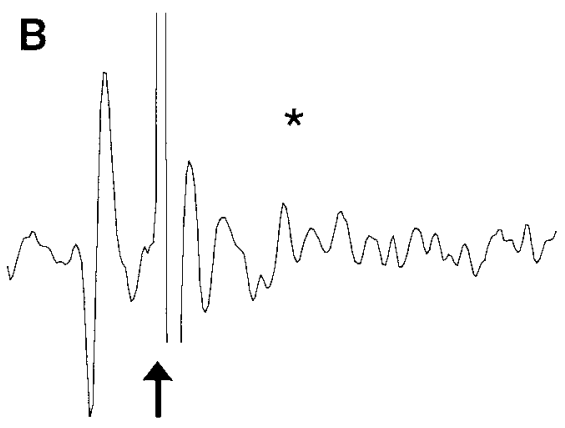

ORTHODROMIC INHIBITION

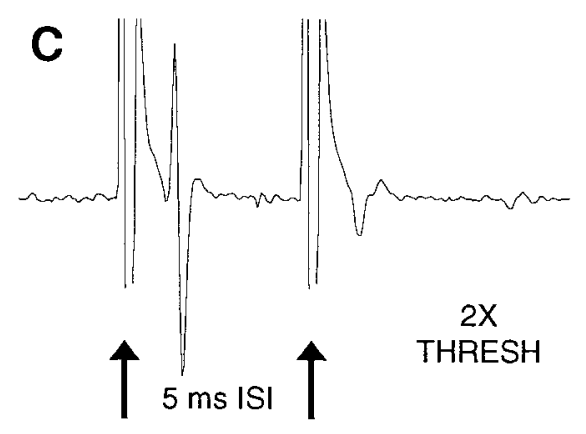

ANTIDROMIC SUPEREXCITABILITY

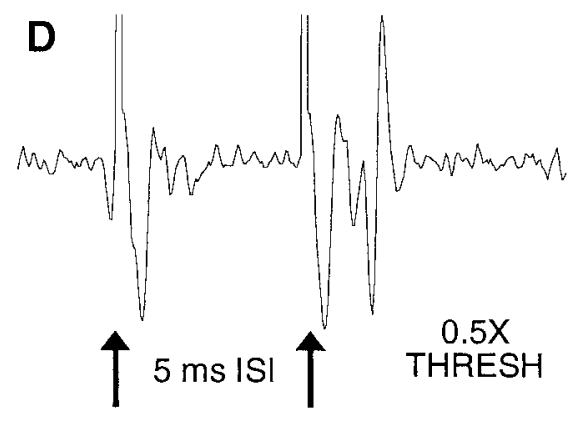

Figure 3. VTA nondopamine neuron reciprocal input to cortex: extracellular recordings. $A$, Stimulation of the IC elicits a VTA non-DA spike (filled circle). B, A spontaneous spike that precedes IC stimulation extinguishes the driven spike. Calibration bar in $A$ applies to $B$. The asterisk signifies where the driven spike would have occurred had there been no collision. $C$, Stimulation of the IC also elicits orthodromic VTA non-DA spikes and produces a period of inhibition of an orthodromic spike that extends to $20 \mathrm{msec}$ $(C)$ when tested with equipotent paired stimuli at a $2 \times$ threshold stimulus level. $D$, IC stimulation produces a period of superexcitability for an antidromic spike when tested with equipotent paired stimuli at a $0.5 \times$ threshold stimulus level. Arrows indicate IC stimulus artifacts. The time between arrows or the interstimulus interval (ISI) in $C$ and $D$ is indicated in each graph. $(n=5)$. Occasionally, VTA non-DA spikes could be driven by stimulation of the NAcc; however, the threshold for activation was often so high $(>2.0 \mathrm{~mA})$ and the fidelity of activation was so low that this excitatory input was not considered to be an important one for this study.

\section{Intracellular recording and labeling}

After successful impalement of VTA non-DA neurons, their passive membrane properties and response to IC stimulation were characterized in vivo. VTA non-DA neurons had a mean resting membrane potential of $-61.9 \pm 1.8 \mathrm{mV}(n=18)$, and their mean spike amplitude was $68.3 \pm 2.1 \mathrm{mV}(n=18)$. The $\mathrm{ON}$ period of spontaneous VTA non-DA activity was accompanied by a $9.4 \pm$ $0.9 \mathrm{mV}$ depolarization (Fig. $6 A ; n=8$ ). Spontaneous and orthodromic IC-evoked VTA non-DA intracellular spikes were preceded by an EPSP (Fig. $6 B$ ) whose mean amplitude was $7.6 \pm 0.3$ $\mathrm{mV}$ (Fig. 6C). There appeared to be little or no spontaneous EPSP activity during the OFF phase (Fig. 6A).

As demonstrated in the extracellular recordings in Figure 3, stimulation of the IC evoked both antidromic and orthodromic VTA non-DA spikes. We characterized the reciprocal nature of the corticotegmental input and the tegmentocortical output of intracellularly recorded VTA non-DA neurons in vivo. Figure 7 shows both orthodromic (Fig. 7A) and antidromic (Fig. 7B,C) VTA non-DA spikes driven by stimulation of the IC in two separate neurons recorded intracellularly. The resting membrane potential of the orthodromic-driven spike in Figure $7 A$ was -62 $\mathrm{mV}$, whereas that of the antidromic-driven spike in Figure $7, B$ and $C$, was $-65 \mathrm{mV}$. Antidromicity was determined by the collision test in Figure $7 C$. Orthodromic and spontaneous, but not antidromic, VTA non-DA spikes were preceded by an EPSP.
VTA non-DA neurons responded to depolarizing current steps with multiple spike discharges characterized by a lack of accommodation (Fig. 8A). The number of spike discharges was monotonically related to current intensity (Fig. 8B). Table 1 summarizes the cellular properties of extracellularly and intracellularly recorded VTA non-DA neurons.

\section{Morphological, ultrastructural, and immunocytochemical characterization of VTA non-DA neurons}

All neurons were first characterized via extracellular electrophysiological criteria. After successful impalement, neurobiotin was iontophoretically injected in the neurons for time periods from 5 to $30 \mathrm{~min}$. Of the 22 neurons recorded intracellularly and labeled with neurobiotin in vivo, we were able to find 10 of them with light microscopy. It appeared that a minimum of $10 \mathrm{~min}$ of iontophoretic application combined with intracellular spike activity, both spontaneous and current driven, was required to identify neurobiotin-labeled neurons in the tissue. Neurobiotin-labeled neurons were characteristically multipolar, with two or more dendrites seen in a single plane of section (Fig. 9). Ultrastructural analysis showed that neurobiotin-filled somata and dendrites contained sparse immunogold labeling for GABA (Fig. 10). Neurobiotin- and GABA-labeled dendrites received asymmetric excitatory-type synapses from unlabeled terminals. In addition, these dendrites received synaptic input from other terminals that formed symmetric inhibitory-type synapses. These latter terminals also sometimes contained GABA immunoreactivity. In tissue processed for $\mathrm{TH}$, neurobiotin-filled cell bodies and dendrites did not contain immunogold-silver labeling for $\mathrm{TH}$. 


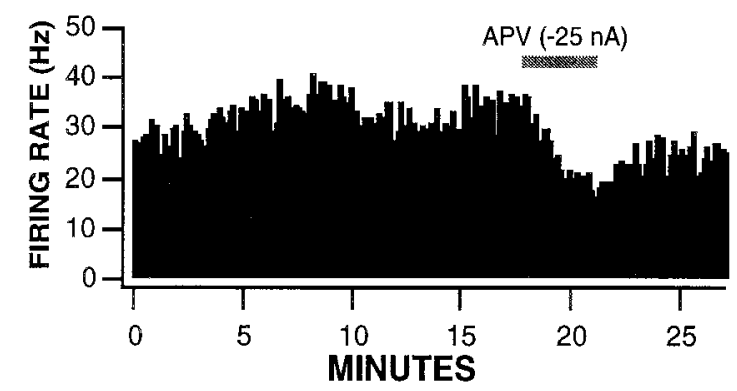

A

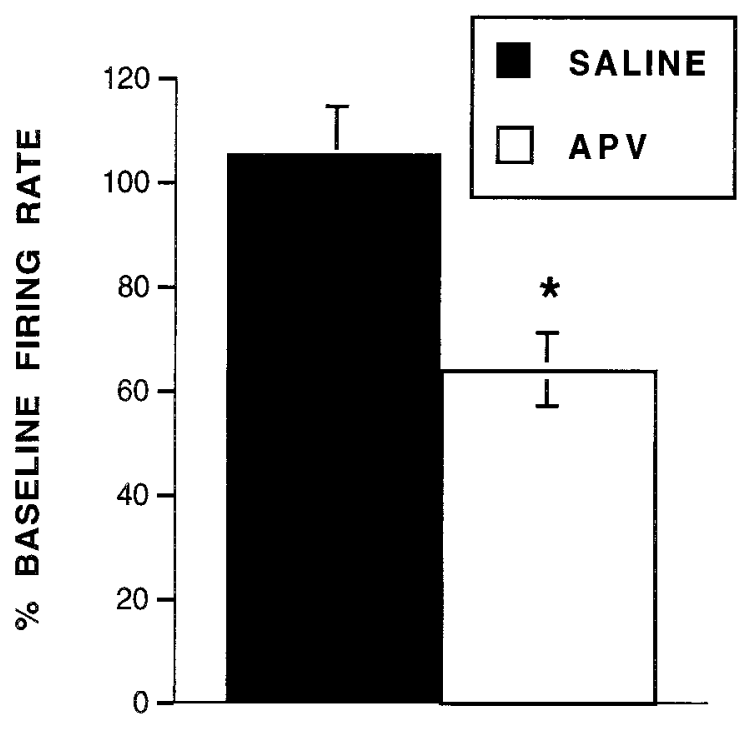

B

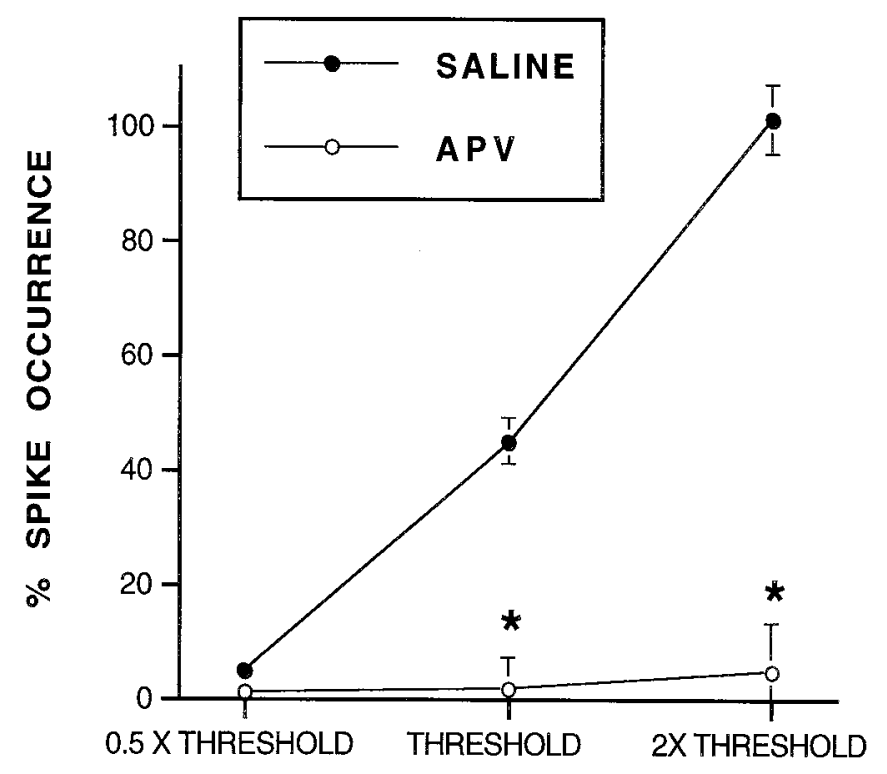

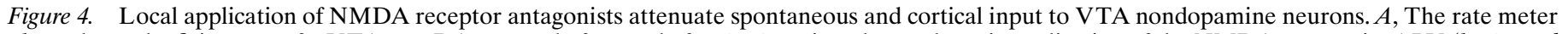

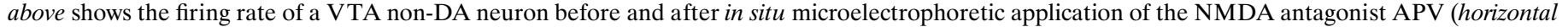

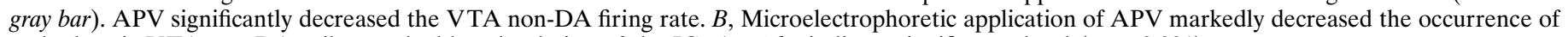
orthodromic VTA non-DA spikes evoked by stimulation of the IC. Asterisks indicate significance level $(p<0.001)$.

\section{DISCUSSION}

\section{VTA nondopamine neurons are GABAergic projection neurons}

Using electrophysiological and anatomical techniques, we have identified, with stringent criteria, a homogeneous population of non-DA neurons in the VTA. They are rapid-firing, nonbursting neurons with reciprocal innervation from the cortex and inhibitory input from the NAcc indicating that these neurons influence and are influenced by cortical and limbic structures. They also contain GABA immunoreactivity and receive excitatory-type synapses from unlabeled terminals and symmetric inhibitory-type synapses from terminals that sometimes contain GABA immunoreactivity. These findings indicate that VTA non-DA neurons are GABAergic and are also subject to GABA inhibition. The prevailing view is that VTA non-DA neurons are local circuit interneurons (Beart and McDonald, 1980; O'Brien and White, 1987; Churchill et al., 1992); however, VTA non-DA neurons may also project to the cortex and ventral striatum (Thierry et al., 1980). Furthermore, the neurotransmitter used by both local and projection neurons in the VTA, similar to that used by non-DA neurons in the substantia nigra, is thought to be GABA (Nagai et al., 1983; Otterson and Storm-Mathisen, 1984; Mugnaini and Oertel, 1985). This is supported by studies showing that
GABAergic terminals provide synaptic input to DA neurons in the VTA (O'Brien and White, 1987; Carlsson and Carlsson, 1990; Bayer and Pickel, 1991).

VTA non-DA neurons were driven antidromically by IC stimulation, indicating that they were not mere local circuit interneurons but that they project to cortical sites as well. Regardless of whether or not the input to VTA non-DA neurons was orthodromic or antidromic, brief, high-frequency stimulation of the IC elicited multiple spike discharging, which was optimal at $200 \mathrm{~Hz}$. One possible explanation for this marked frequency-dependent hyperexcitability is that the interval corresponding to $200 \mathrm{~Hz}$ (i.e., $5 \mathrm{msec}$ ) is within the superexcitable period for the antidromic input, whereas 2.5 and $20 \mathrm{msec}$ intervals, corresponding to 400 and $50 \mathrm{~Hz}$, are near or beyond the time domain for the superexcitable period for the antidromic input. Superexcitability is a ubiquitous feature of excitable membranes in which the threshold for spike elicitation by a conditioned stimulus is lowered by either a depolarization-induced local increase in external potassium concentration or by a hyperpolarization-induced reduction in sodium inactivation (Raymond and Lettvin, 1978). The $5 \mathrm{msec}$ interval corresponding to the $200 \mathrm{~Hz}$ stimulation is also within the inhibitory period for the IC-driven orthodromic input in which multiple discharging of VTA non-DA neurons would not 
A
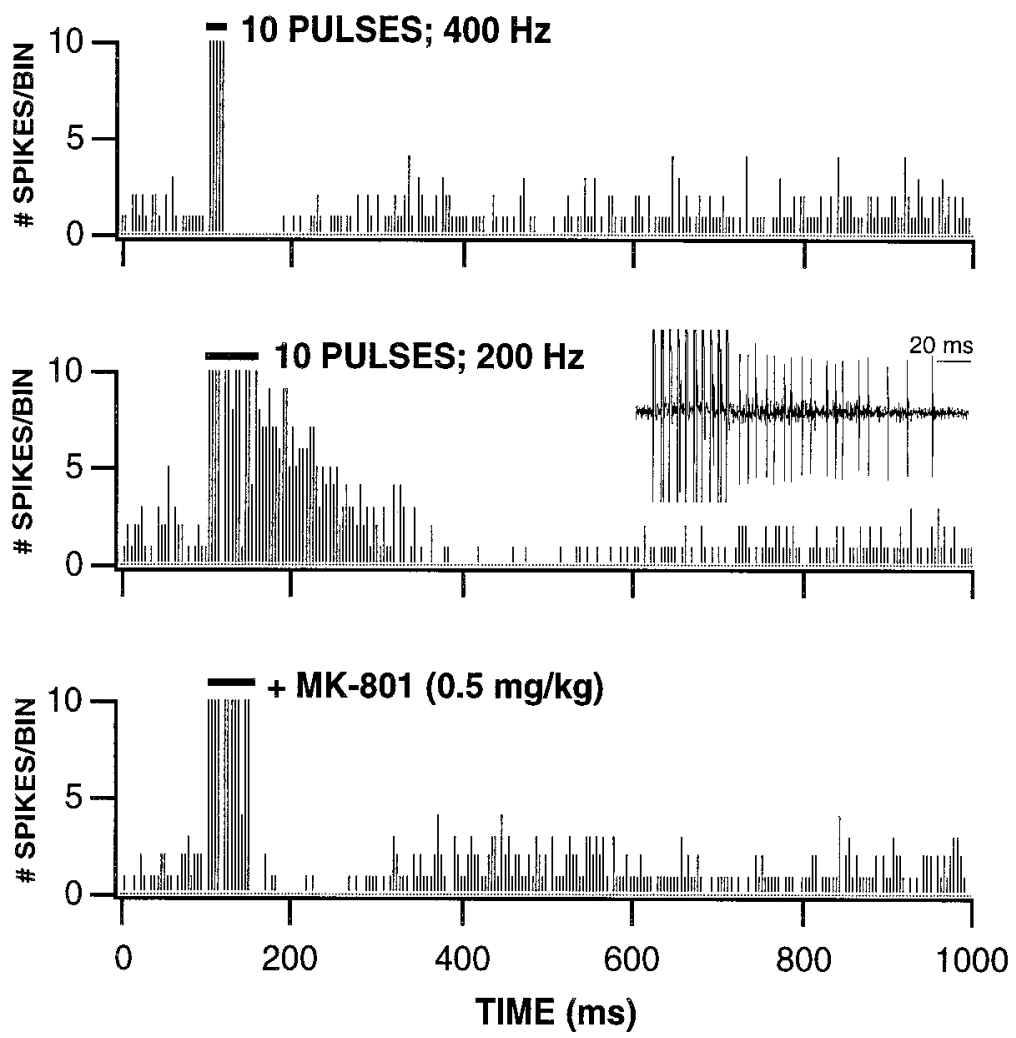

B

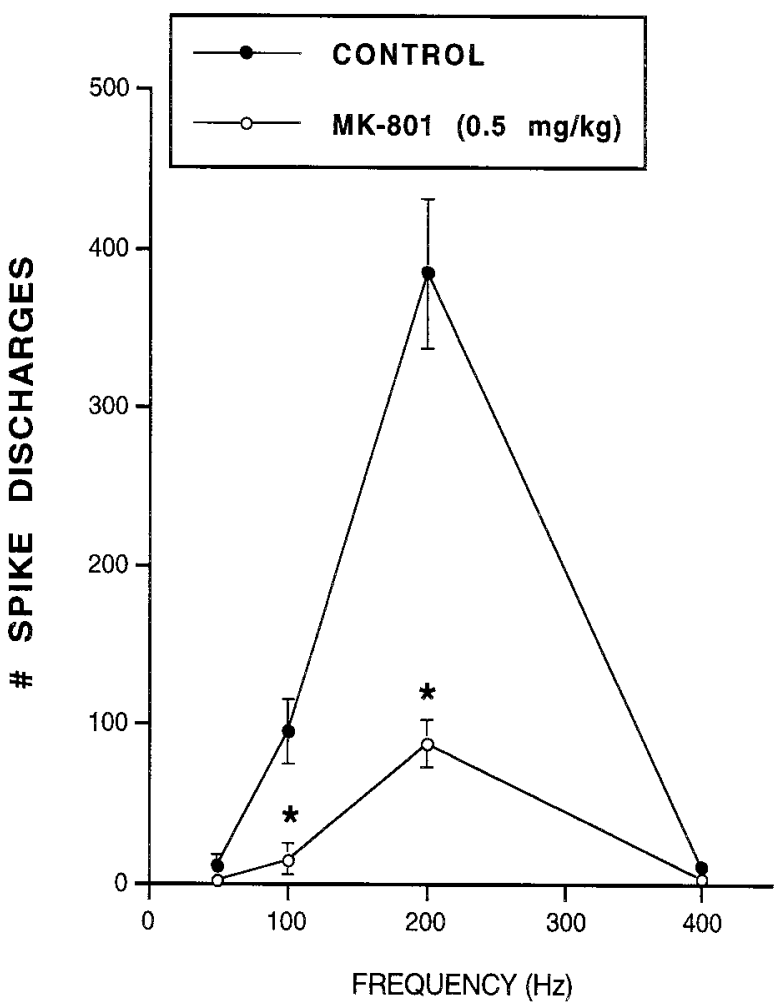

Figure 5. Systemic administration of NMDA receptor antagonists attenuate frequency-dependent multiple spike discharges evoked by stimulation of cortical input to VTA nondopamine neurons. $A$, These peristimulus spike histograms demonstrate the effects of high-frequency stimulation of the IC on VTA non-DA spike discharges. Each histogram represents 10 cumulated epochs of IC stimulation $(0.1 \mathrm{~Hz}$; bin width, 2 msec). Stimulation of the IC with 10 pulses at $400 \mathrm{~Hz}$ did not evoke spike discharges but produced a $100 \mathrm{msec}$ period of inhibition of spontaneous firing (top), whereas the same number of pulses at $200 \mathrm{~Hz}$ elicited multiple spike discharges that occurred with latencies nearly an order of magnitude greater than the single spike latency of 2-3 msec (middle). The inset shows a representative filtered recording of a VTA non-DA neuron after high-frequency stimulation (200 Hz; 10 pulses) of the IC. Systemic administration of the NMDA receptor antagonist MK-801 markedly suppressed the multiple discharging of this VTA non-DA neuron (bottom). The horizontal bar in each histogram represents the stimulus train. $B$, Summary of the VTA non-DA spike discharges produced by high-frequency IC stimulation shows that the number of spike discharges is a function of the frequency of stimuli. For all frequencies, the number of pulses and the number of epochs were held constant at 10 while varying the interval between pulses. Although 50 and $400 \mathrm{~Hz}$ evoked little or no spike discharges, $200 \mathrm{~Hz}$ markedly and $100 \mathrm{~Hz}$ moderately increased discharging. Systemic administration of MK-801 significantly reduced VTA non-DA spike discharging produced by IC stimulation across frequencies. Asterisks indicate significance level $(p<0.001)$.

be expected; therefore, a role for disinhibition can probably be discounted. It is reasonable that the multiple discharging of VTA non-DA neurons results from feedforward excitation from neighbor VTA non-DA neurons that are activated antidromically by IC stimulation.

\section{VTA nondopamine neuron spontaneous firing is dependent on synaptic input}

The two most distinguishing features of VTA non-DA neurons under halothane anesthesia were their relatively fast firing rates and their phasic activity. We have recently demonstrated in preliminary studies that this persistent phasic activity seems to result from the anesthesia because the activity of VTA non-DA neurons in freely behaving rats is regular and contingent on cortical arousal (Steffensen et al., 1996). Moreover, in the anesthetized preparation, neither IC stimulation nor application of NMDA antagonists modified the phasic activity. VTA non-DA neurons were characteristically fast-firing neurons, perhaps because of their somewhat depolarized resting membrane potential.
Nearly every VTA non-DA spike was preceded by an appreciable EPSP, suggesting that the spontaneous activity of these neurons is strongly regulated by excitatory input.

Many studies have emphasized the role of intrinsic membrane properties to explain the rate and pattern of firing of midbrain DA neurons (Grace and Bunney, 1984a,b; Llinas et al., 1984; Kita et al., 1986; Nedergaard and Greenfield, 1992; Kang and Kitai, 1993). There are, however, significant differences between the spontaneous activity of SN and VTA DA neurons in vitro and in vivo (Bunney et al., 1973; Wilson et al., 1977; Kita et al., 1986), suggesting that afferent input plays a role in modulating the activity, particularly the firing pattern, of these neurons. In support of this hypothesis, most VTA non-DA neurons in the in vitro slice preparation are quiescent (Wang and French, 1995). The VTA non-DA neurons described in the in vitro study share similar characteristics to those described here, including an action potential duration of $<1.0 \mathrm{msec}$, a mean resting membrane potential of $-60.8 \pm 2.6 \mathrm{mV}$, and a lack of rectification to hyperpolarizing current steps. When considered together, these findings strongly 
suggest that the firing rate of VTA non-DA neurons is a function of afferent input.

\section{Corticotegmental NMDA receptor-mediated input to VTA nondopamine neurons}

During the OFF component of phasic activity, EPSPs were not evident in VTA non-DA neurons, suggesting either that the
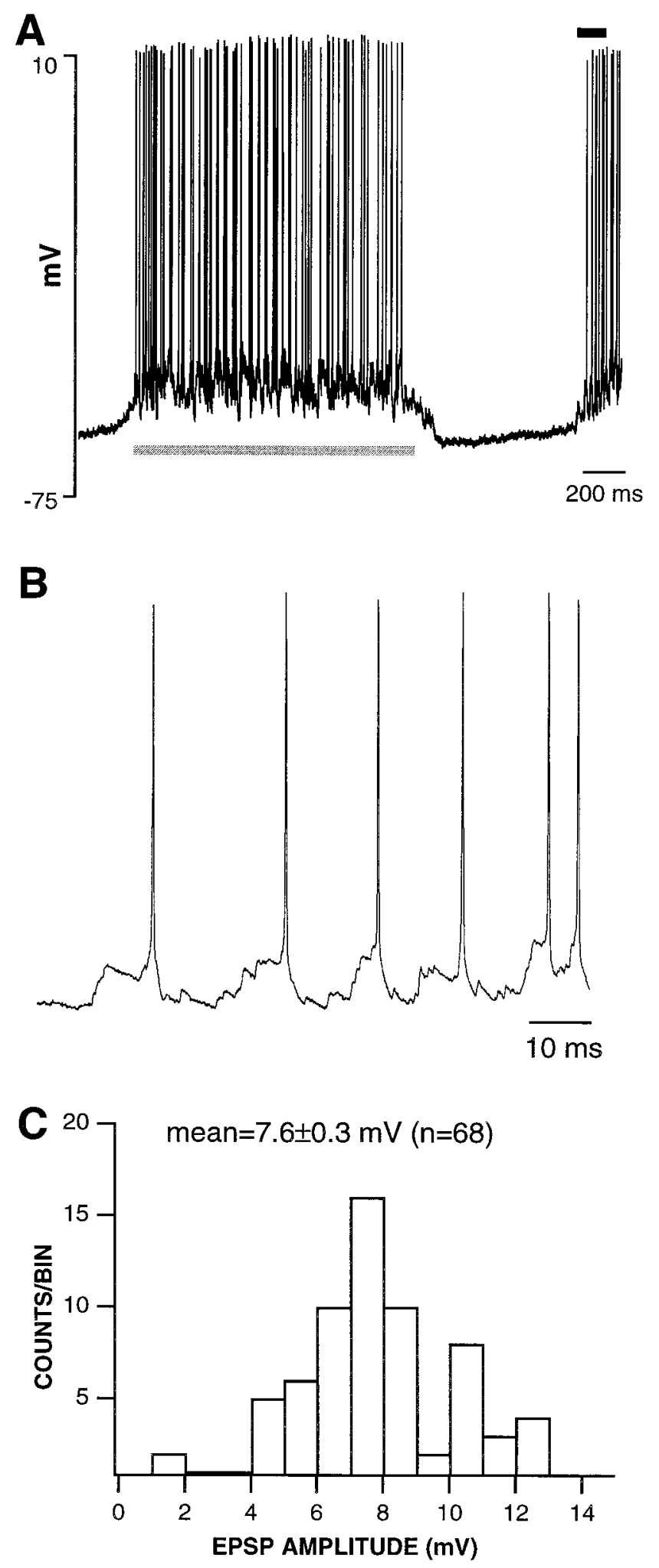

intrinsic activity of these neurons is coincident with excitatory input or that spiking results from an EPSP that is predominantly NMDA receptor-mediated and under a voltage-dependent $\mathrm{Mg}^{2+}$ block typical of neurons at $60-65 \mathrm{mV}$, the characteristic average resting membrane potential of these neurons. This situation would be somewhat unique because EPSPs are usually associated with an initial non-NMDA receptor-mediated current that is followed by NMDA receptor-mediated currents. Local or systemic application of NMDA receptor antagonists moderately reduced the firing rate of VTA non-DA neurons and markedly reduced VTA non-DA spikes elicited by single and tetanic stimulation of the IC, supporting a role for NMDA receptors in mediating glutamatergic corticotegmental neurotransmission under both physiological and supraphysiological conditions. There is substantial evidence demonstrating that both DA and non-DA neurons receive monosynaptic innervation from prefrontal cortical neurons (Christie et al., 1985; Sesack and Pickel, 1992) and that stimulation of the prefrontal cortex evokes excitatory responses on VTA DA and non-DA neurons (Thierry et al., 1979, 1980). NMDA and non-NMDA receptors, including AMPA and kainate receptors, have also been located on VTA DA and non-DA neurons and are activated by glutamate receptor agonists (Kalivas et al., 1989; Seutin et al., 1990; Wang and French, 1993, 1995).

It has been proposed that VTA DA neurons may be regulated by both a direct excitatory corticofugal input to DA neurons and, indirectly, an inhibitory input comprising corticofugal excitatory inputs onto VTA non-DA neurons (Wang and French, 1995). Therefore, the excitability of VTA DA neurons would result from the net effect of direct excitation and indirect inhibition from non-DA neurons by cortical afferents. The latter may explain why the NMDA receptor blockers MK-801 and phencyclidine excite DA neurons in vivo (Zhang et al., 1993), increase DA release in the NAcc (Mathe et al., 1998), and produce hyperlocomotion (Loscher and Honack, 1992). Corticofugal glutamatergic projections to VTA DA neurons (Wolf, 1998) as well as glutamate receptors (Karler et al., 1989) have also been implicated in the development of behavioral sensitization to psychostimulants, an animal model for the intensification of drug craving believed to underlie human drug addiction. Sensitization results, in part, from a long-term change in mesocorticolimbic DA transmission and may involve a disinhibition of dopamine neurons (Steketee and Kalivas, 1991). The disinhibition of DA neurons may result from decreased excitatory corticofugal drive to VTA non-DA neurons or from increased GABAergic drive from the NAcc onto VTA non-DA neurons. Because of their wideband firing activity, dependency on NMDA receptor-mediated cortical input, and

$\leftarrow$

Figure 6. VTA nondopamine neuron spontaneous activity is dependent on synaptic input. $A$, A representative $2.5 \mathrm{sec}$ trace of a VTA non-DA neuron recorded intracellularly in a halothane-anesthetized rat is shown. The resting membrane potential of this VTA non-DA neuron was -61 $\mathrm{mV}$, and the spike amplitude was $70.5 \mathrm{mV}$. This and all other VTA non-DA neurons were characterized by pronounced phasic ON and OFF activity under halothane anesthesia (see Fig. 1). The ON phase of activity was accompanied by a $10.6 \mathrm{mV}$ depolarization. $B$, The time base during the period indicated by the horizontal black line in $A$ is expanded to show the individual spikes. An EPSP appeared to precede every spontaneous spike. The voltage axis is the same as that in $A$. $C$, The amplitudes of each EPSP during the period indicated by the horizontal gray line in $A$ were measured and plotted in the histogram and were characterized by a normal distribution of spontaneous EPSP amplitudes. The mean EPSP amplitude was $7.6 \pm 0.3 \mathrm{mV}(n=68)$. 

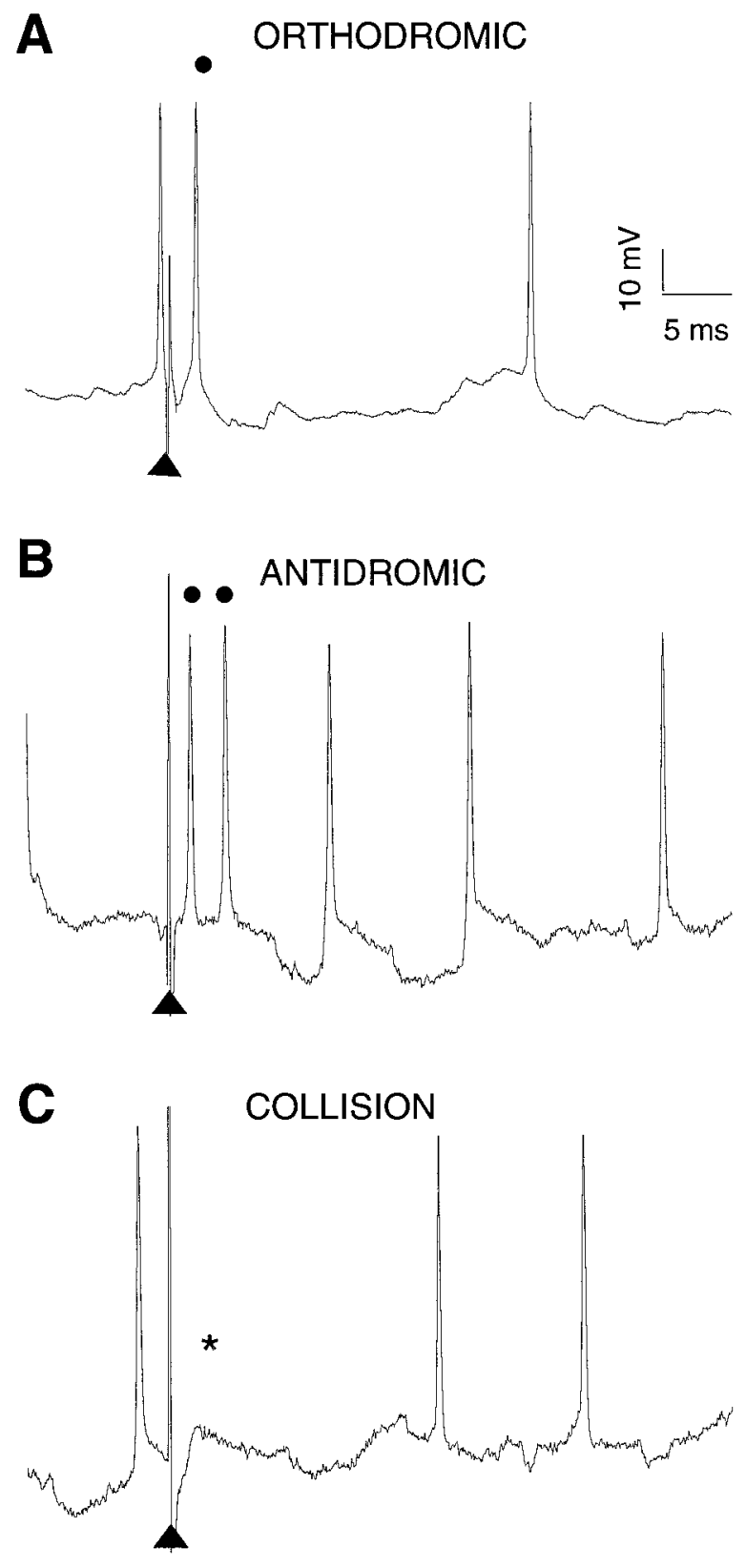

Figure 7. VTA nondopamine neuron reciprocal input to cortex: intracellular recordings. $A$, Similar to that in the extracellular recordings in Figure 3, stimulation of the IC (arrowheads indicate stimulus artifact) consistently evoked intracellularly recorded VTA non-DA spikes at short latency. In this example, the driven spike (filled circle) appeared to be orthodromic because a spontaneous spike occurred within a spontaneousspike to driven-spike interval that was less than twice the latency of the driven spike plus the refractory period. In addition, a small EPSP preceded the driven spike. The spike at the far right was a spontaneous spike and was not time-locked to successive stimuli. $B$, This VTA non-DA spike doublet was driven antidromically from the IC. Spike doublets occurred more with intracellular than with extracellular recordings. Note that there is little or no EPSP preceding the doublet of short latency spikes even though the spontaneous spikes are accompanied by EPSPs. $C$, The doublet of IC-driven spikes is extinguished by a spontaneous spike that occurs within an interval that was less than twice the latency of the first driven spike plus the refractory period. The asterisk indicates where the spikes would have occurred in the absence of collision. The calibration bars in $A$ apply to $B$ and $C$. inhibitory modulation by the NAcc, VTA non-DA neurons may contribute to plasticity in the complex neuronal circuits underlying behavioral sensitization. We hypothesize that these neurons receive a physiologically relevant NMDA receptor-mediated input that paces GABA inhibition to DA neurons in a manner similar to the role played by thalamic inputs to substantia nigra pars reticulata GABAergic neurons in mediating inhibition of SNc DA neurons (Tepper et al., 1995).

\section{Potential role for VTA nondopamine neurons in mesocorticolimbic neurotransmission and reward}

We have recently reported preliminary work indicating that VTA non-DA firing rates increase markedly during the onset of movement and decrease markedly with select anesthetics (Steffensen et al., 1996). In addition, the firing rate of VTA non-DA neurons decreased $42 \%$ during slow-wave sleep and increased $114 \%$ during REM sleep, relative to wakefulness (Lee et al., 1997). These findings suggest that VTA non-DA neurons may regulate cortical arousal and psychomotor systems. Furthermore, recent preliminary work has indicated that VTA non-DA firing rates also decrease during the acquisition of heroin self-administration behavior but soon after desensitize, providing further evidence that VTA non-DA neurons are involved in psychomotor-related events (Lee et al., 1996). If an increase in the mesolimbic dopaminergic tone is important in brain-reward mechanisms (Wise and Rompre, 1989), it is reasonable that GABA inhibition of DA neurons by VTA non-DA neurons may be an important mechanism of regulation. In support of this hypothesis, it has recently been demonstrated that self-administration of GABA antagonists into the VTA is blocked by D2 receptor antagonists (David et al., 1997).

It is unlikely that ascending DA fibers serve as the transducers of intracranial self-stimulation (ICSS) reward. These conclusions are based mostly on medial forebrain bundle (MFB) refractory period measurements that determined that the primary effector of reward was not mesencephalic DA neurons (Gallistel et al., 1981). It was determined that the refractory period of the neurons directly activated by ICSS lies in the range of $0.4-1.3 \mathrm{msec}$ (Yeomans, 1979), the conduction velocity along the path was $1.0-4.5 \mathrm{~m} / \mathrm{sec}$, the direction was descending in the MFB, and there was an axonal linkage between the lateral hypothalamus and the VTA (Shizgal et al., 1982). Collectively, these conclusions have been known as the "descending path hypothesis" (Wise, 1980a; Shizgal et al., 1982; Gallistel, 1983). This makes it likely that the axons were myelinated fibers, unlike catecholaminergic fibers that are unmyelinated and have refractory periods in the range of 1.8-2.0 msec (Guyenet and Aghajanian, 1978; Maeda and Mogenson, 1981). Thus, it has been hypothesized that the neuronal transducers of reward send fibers that descend and synapse on DA neurons of the VTA (Wise, 1980b; Murray and Shizgal, 1994), where their anatomical dispersion corresponds to the dispersion of VTA DA neurons (Wise, 1982). GABAergic VTA non-DA neurons had conduction velocities of $2.4 \pm 0.2$ $\mathrm{m} / \mathrm{sec}$ and absolute (measured at $2 \times$ threshold) refractory periods averaging $0.6 \pm 0.1 \mathrm{msec}$. The relatively fast conduction velocity and the short refractory period of these neurons are within the range for a neuronal transducer of reward.

Dopamine-independent mechanisms may be involved in the reinforcing properties of drugs of abuse because findings from several laboratories have questioned the notion that DAdependent mechanisms are the final common pathway in the processes mediating reinforcement. These studies have shown 

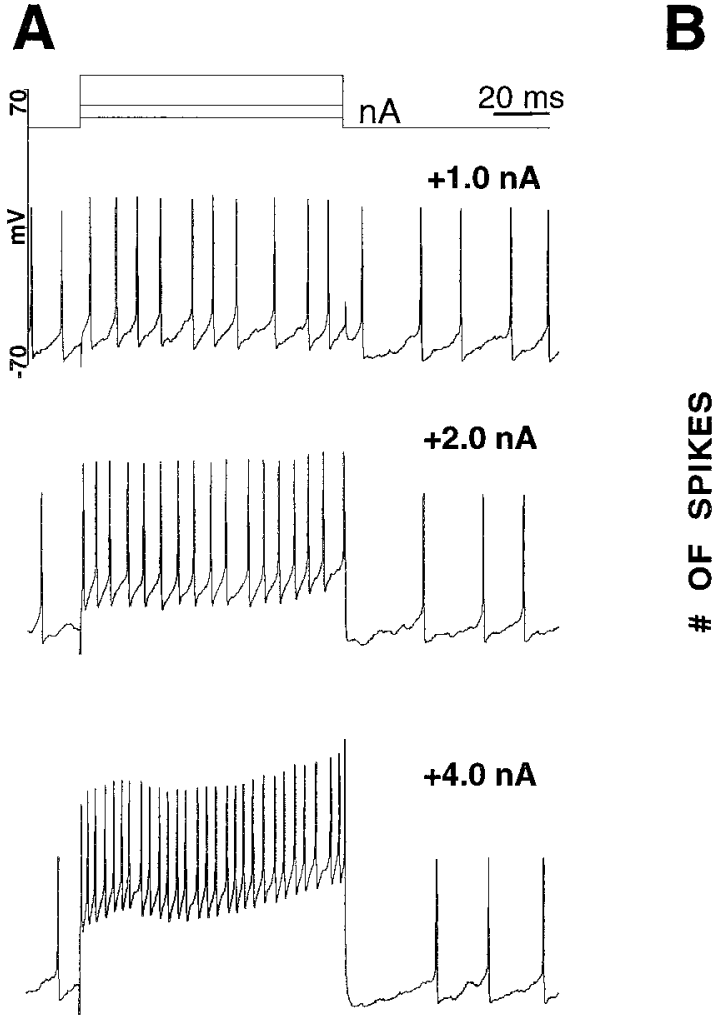

B

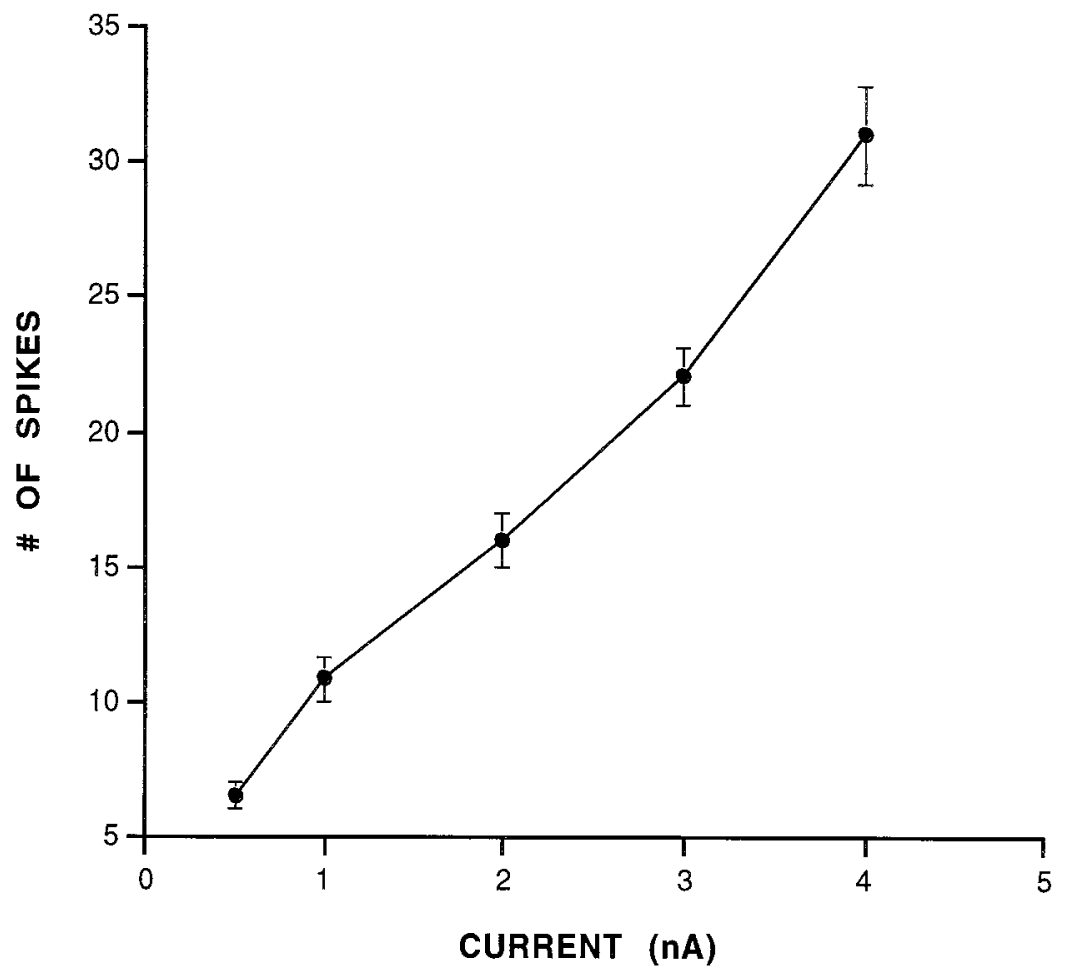

Figure 8. Lack of accommodation in VTA nondopamine neurons. This neuron had a resting membrane potential of $-64 \mathrm{mV}$. $A$, Increasing levels of depolarizing current produced multiple VTA non-DA spiking. Current steps are shown above the traces. The calibration bar (top) is the same for all traces. $B$, Summary of the input/output response for spiking produced by depolarizing current demonstrates the lack of accommodation of VTA non-DA neurons.

\begin{tabular}{lr}
\hline $\begin{array}{l}\text { Table 1. Cellular properties of extracellularly and intracellularly } \\
\text { recorded VTA nondopamine neurons }\end{array}$ \\
Cellular properties & Mean $\pm \mathrm{SEM}(n)$ \\
\hline Firing rate & $19.1 \pm 1.4 \mathrm{~Hz}(122)$ \\
Period of phasic activity & $0.43 \pm 0.07 \mathrm{~Hz}(25)$ \\
Spike duration (50\% amplitude) & $310 \pm 10 \mu \mathrm{sec}(93)$ \\
Conduction velocity via IC & $2.4 \pm 0.2 \mathrm{msec}(23)$ \\
Refractory period via IC & $0.6 \pm 0.1 \mathrm{msec}(15)$ \\
Latency via IC (antidromic) & $2.1 \pm 0.2 \mathrm{msec}(23)$ \\
Latency via IC (orthodromic) & $3.2 \pm 0.3 \mathrm{msec}(72)$ \\
Period of inhibition via IC & $116.7 \pm 24 \mathrm{msec}(6)$ \\
Period of inhibition via NAcc & $75.0 \pm 11 \mathrm{msec}(4)$ \\
Resting membrane potential & $-61.9 \pm 1.8 \mathrm{mV}(18)$ \\
Action potential amplitude & $68.3 \pm 2.1 \mathrm{mV} \mathrm{(18)}$ \\
ON phase depolarization amplitude & $9.4 \pm 0.9 \mathrm{mV} \mathrm{(8)}$ \\
EPSP amplitude (cell in Fig. 8$)$ & $7.6 \pm 0.3 \mathrm{mV}(68)$ \\
\end{tabular}

that chemical destruction of DA terminals in the NAcc with 6-OHDA had no effect on morphine or heroin selfadministration (Ettenberg et al., 1982; Pettit et al., 1984; Dworkin et al., 1988). Furthermore, a lack of DA involvement in drug reinforcement has also been demonstrated for oral ethanol selfadministration (Rassnick et al., 1993) and conditioned place preference (Cunningham and Noble, 1992; Risinger et al., 1992) as well as for cocaine self-administration (Goeders and Smith, 1983)

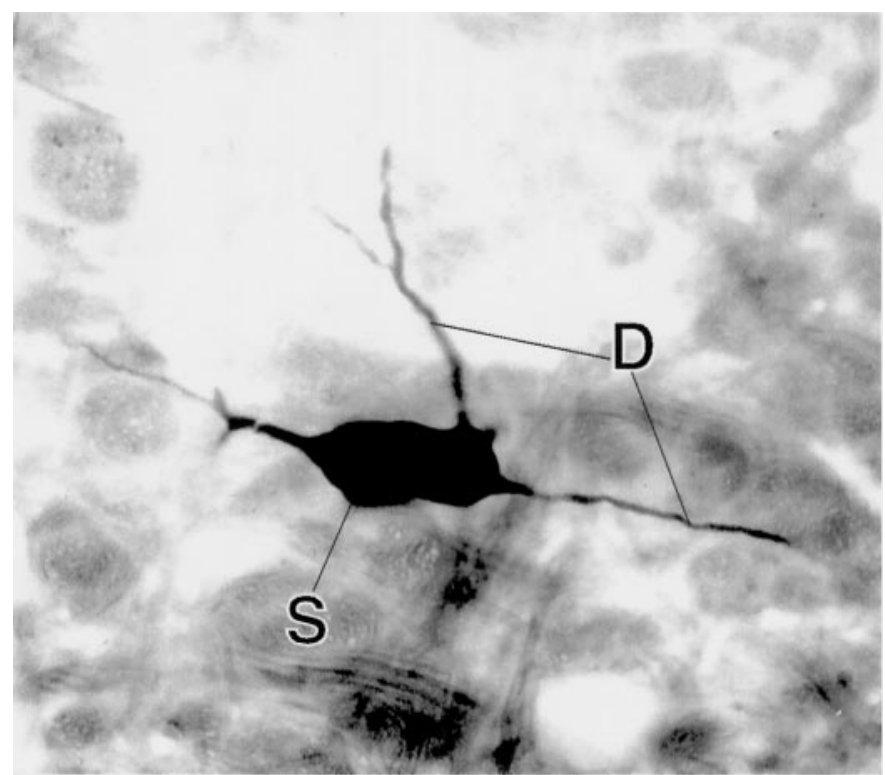

Figure 9. Neurobiotin labeling of VTA nondopamine neurons in vivo. Light micrograph of a neurobiotin-labeled non-DA neuron in the VTA. This is the same neuron studied electrophysiologically in Figure 8. This neuron was characteristic of all neurons identified electrophysiologically as VTA non-DA neurons and was multipolar in shape with few dendritic processes $(D)$ branching from its soma $(S)$. 


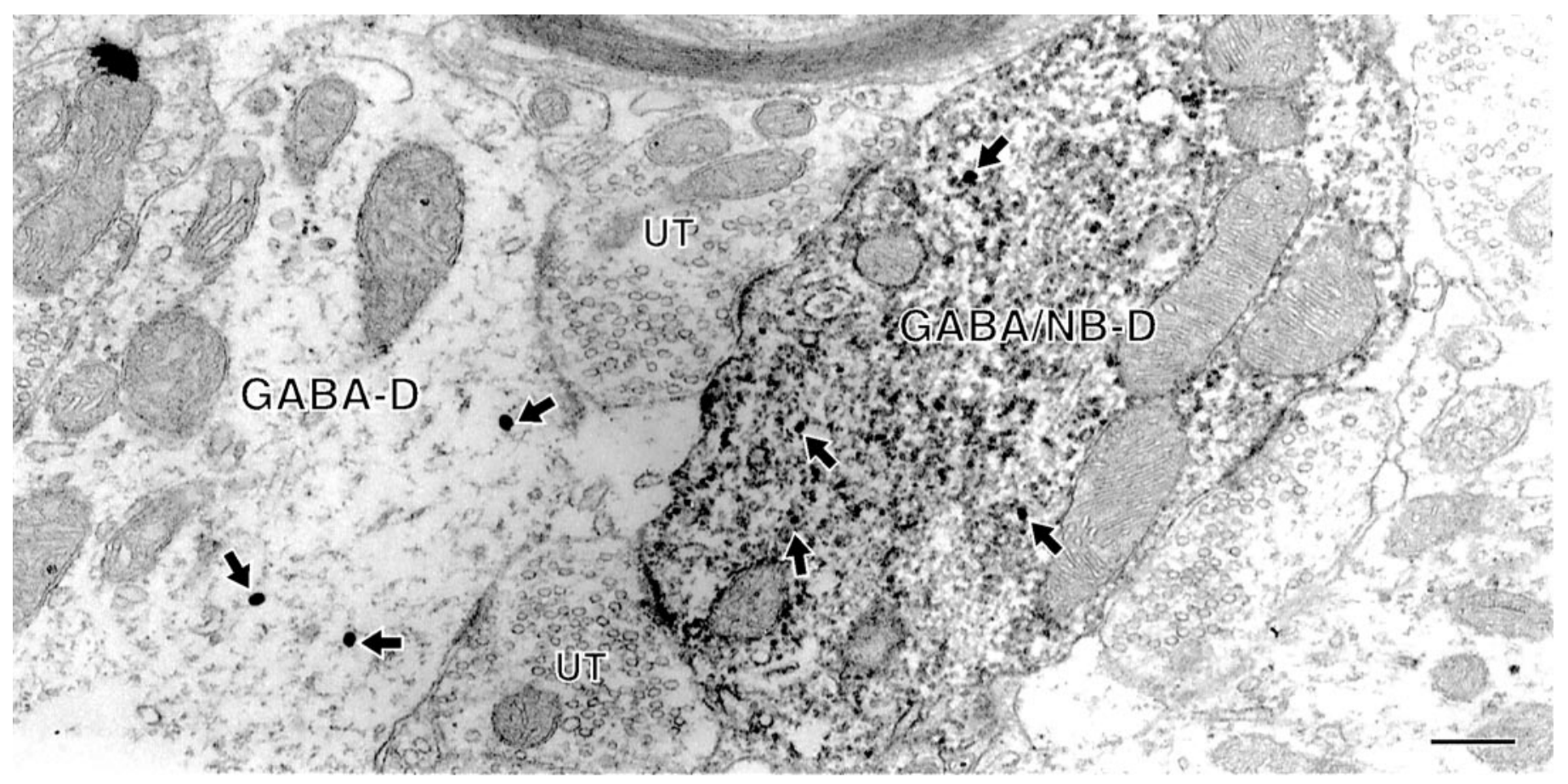

Figure 10. VTA nondopamine neurons contain GABA immunoreactivity. Electron micrograph of the neuron in Figure 9 shows two dendrites $(G A B A-D$ and $G A B A / N B-D)$ that contain immunogold-silver particles for GABA (arrows). $G A B A / N B-D$ also contains peroxidase reaction product for neurobiotin, indicative of the physiologically characterized non-DA neuron. The filled and nonfilled GABA dendrites are linked by two common axon unlabeled terminals (UTs), which appear to form asymmetric synapses. The gold-silver particles for GABA are sparse but are indicative of specific labeling because there is virtually a total absence of spurious particles in the tissue. Scale bar, $0.4 \mu \mathrm{m}$.

and conditioned place preference (Spyraki et al., 1982; Mackey and Van der Kooy, 1985). More recently, the role of DA in cocaine self-administration has been called into question by studies demonstrating that DA-transporter knock-out mice continue to self-administer cocaine (Rocha et al., 1998). Taken together, these studies and the findings presented here provide evidence of the existence of non-DA pathways that also play a role in mediating the reinforcing or rewarding properties of drugs.

\section{REFERENCES}

Bayer VE, Pickel VM (1991) GABA-labeled terminals form proportionally more synapses with dopaminergic neurons containing low densities of tyrosine hydroxylase-immunoreactivity in rat ventral tegmental area. Brain Res 559:44-55.

Beart PM, McDonald D (1980) Neurochemical studies of the mesolimbic dopaminergic pathway: somatodendritic mechanisms and GABAergic neurones in the rat ventral tegmentum. J Neurochem 34:1622-1629.

Beckstead RM, Domesick VB, Nauta WJ (1979) Efferent connections of the substantia nigra and ventral tegmental area in the rat. Brain Res 175:191-217.

Bunney BS, Aghajanian GK, Roth RH (1973) Comparison of effects of L-dopa, amphetamine and apomorphine on firing rate of rat dopaminergic neurons. Nat New Biol 245:123-125.

Carlin RK, Grab DJ, Cohen RS, Siekevitz P (1980) Isolation and characterization of postsynaptic densities from various brain regions: enrichment of different types of postsynaptic densities. J Cell Biol 86:831-845.

Carlsson M, Carlsson A (1990) Interactions between glutamatergic and monoaminergic systems within the basal ganglia-implications for schizophrenia and Parkinson's disease. Trends Neurosci 13:272-276.

Chiodo LA (1988) Dopamine-containing neurons in the mammalian central nervous system: electrophysiology and pharmacology. Neurosci Biobehav Rev 12:49-91.
Christie MJ, Bridge S, James LB, Beart PM (1985) Excitotoxin lesions suggest an aspartatergic projection from rat medial prefrontal cortex to ventral tegmental area. Brain Res 333:169-172.

Churchill L, Dilts RP, Kalivas PW (1992) Autoradiographic localization of gamma-aminobutyric acidA receptors within the ventral tegmental area. Neurochem Res 17:101-106.

Cunningham CL, Noble D (1992) Conditioned activation induced by ethanol: role in sensitization and conditioned place preference. Pharmacol Biochem Behav 43:307-313.

David V, Durkin TP, Cazala P (1997) Self-administration of the GABAA antagonist bicuculline into the ventral tegmental area in mice: dependence on D2 dopaminergic mechanisms. Psychopharmacology (Berl) 130:85-90.

Dworkin SI, Guerin GF, Lo L, Goeders NE, Smith JE (1988) Lack of an effect of 6-hydroxydopamine lesions of the nucleus accumbens on intravenous morphine self-administration. Pharmacol Biochem Behav 30:1051-1057.

Ettenberg A, Pettit HO, Bloom FE, Koob GF (1982) Heroin and cocaine intravenous self-administration in rats: mediation by separate neural systems. Psychopharmacology (Berl) 78:204-209.

Fallon JH, Moore RY (1978) Catecholamine innervation of the basal forebrain. IV. Topography of the dopamine projection to the basal forebrain and neostriatum. J Comp Neurol 180:545-580.

Gallistel CR (1983) Self-stimulation. The physiological basis of memory, pp 269-349. New York: Academic.

Gallistel CR, Shizgal P, Yeomans JS (1981) A portrait of the substrate for self-stimulation. Psychol Rev 88:228-273.

Goeders NE, Smith JE (1983) Cortical dopaminergic involvement in cocaine reinforcement. Science 221:773-775.

Grace AA, Bunney BS (1983) Intracellular and extracellular electrophysiology of nigral dopaminergic neurons. Identification and characterization. Neuroscience 10:301-315.

Grace AA, Bunney BS (1984a) The control of firing pattern in nigral dopamine neurons: single spike firing. J Neurosci 4:2866-2876.

Grace AA, Bunney BS (1984b) The control of firing pattern in nigral dopamine neurons: burst firing. J Neurosci 4:2877-2890. 
Grace AA, Onn S-P (1989) Morphology and electrophysiological properties of immunocytochemically identified rat dopamine neurons recorded in vitro. J Neurosci 9:3463-3481.

Guyenet PG, Aghajanian GK (1978) Antidromic identification of dopaminergic and other output neurons of the rat substantia nigra. Brain Res 130:69-84.

Hsu SM, Raine L, Fanger H (1981) Use of avidin-biotin-peroxidase complex $(\mathrm{ABC})$ in immunoperoxidase techniques: a comparison between ABC and unlabeled antibody (PAP) procedures. J Histochem Cytochem 29:577-580.

Kalivas PW, Duffy P (1993) Time course of extracellular dopamine and behavioral sensitization to cocaine. II. Dopamine perikarya. J Neurosci 13:276-284.

Kalivas PW, Duffy P, Barrow J (1989) Regulation of the mesocorticolimbic dopamine system by glutamic acid receptor subtypes. J Pharmacol Exp Ther 251:378-387.

Kang Y, Kitai ST (1993) Calcium spike underlying rhythmic firing in dopaminergic neurons of the rat substantia nigra. Neurosci Res 18:195-207.

Karler R, Calder LD, Chaudhry IA, Turkanis SA (1989) Blockade of "reverse tolerance" to cocaine and amphetamine by MK-801. Life Sci 45:599-606.

Kita T, Kita H, Kitai ST (1986) Electrical membrane properties of rat substantia nigra compacta neurons in an in vitro slice preparation. Brain Res 372:21-30.

Koob GF, Le Moal M (1997) Drug abuse: hedonic homeostatic dysregulation. Science 278:52-58

Lacey MG, Mercuri NB, North RA (1989) Two cell types in rat substantia nigra zona compacta distinguished by membrane properties and the actions of dopamine and opioids. J Neurosci 9:1233-1241.

Le Moal M, Cardo B, Stinus L (1969) Influence of ventral mesencephalic lesions on various spontaneous and conditional behaviors in the rat. Physiol Behav 4:567-574.

Le Moal M, Galey D, Cardo B (1975) Behavioral effects of local injection of 6-hydroxydopamine in the ventral tegmentum in the rat. Possible role of the mesolimbic dopaminergic system. Brain Res 88:190-194.

Lee R-S, Griffin P, Steffensen SC, Casalman S, Henriksen S (1996) Responses of nucleus accumbens and VTA non-dopamine neurons to heroin in freely-moving rats. Soc Neurosci Abstr 22:174.

Lee R-S, Steffensen SC, Henriksen SJ (1997) Ventral tegmental area non-dopamine neuronal activity during cortical arousal. Soc Neurosci Abstr 23:793.

Llinas R, Greenfield SA, Jahnsen H (1984) Electrophysiology of pars compacta cells in the in vitro substantia nigra-a possible mechanism for dendritic release. Brain Res 294:127-132.

Loscher W, Honack D (1992) The behavioural effects of MK-801 in rats: involvement of dopaminergic, serotonergic and noradrenergic systems. Eur J Pharmacol 215:199-208.

Mackey WB, Van der Kooy D (1985) Neuroleptics block the positive reinforcing effects of amphetamine but not morphine as measured by place conditioning. Pharmacol Biochem Behav 22:101-105.

Maeda H, Mogenson GJ (1981) A comparison of the effects of electrical stimulation of the lateral and ventromedial hypothalamus on the activity of neurons in ventral tegmental area and substantia nigra. Brain Res Bull 7:283-291.

Mathe JM, Nomikos GG, Schilstrom B, Svensson TH (1998) NonNMDA excitatory amino acid receptors in the ventral tegmental area mediate systemic dizocilpine (MK-801) induced hyperlocomotion and dopamine release in the nucleus accumbens. J Neurosci Res 51:583-592.

Mugnaini E, Oertel W (1985) An atlas of the distribution of GABAergic neurons and terminals in the rat CNS as revealed by GAD immunohistochemistry. In: Handbook of chemical neuroanatomy, pp 436-608. Amsterdam: Elsevier.

Murray B, Shizgal P (1994) Evidence implicating both slow- and fastconducting fibers in the rewarding effect of medial forebrain bundle stimulation. Behav Brain Res 63:47-60.

Nagai T, McGeer PL, McGeer EG (1983) Distribution of GABA-T intensive neurons in the rat forebrain and midbrain. J Comp Neurol 218:220-238.

Nedergaard S, Greenfield SA (1992) Sub-populations of pars compacta neurons in the substantia nigra: the significance of qualitatively and quantitatively distinct conductances. Neuroscience 48:423-437.
O'Brien DP, White FJ (1987) Inhibition of non-dopamine cells in the ventral tegmental area by benzodiazepines: relationship to A10 dopamine cell activity. Eur J Pharmacol 142:343-354.

Otterson OP, Storm-Mathisen J (1984) Neurons containing or accumulating transmitter amino acids. In: Handbook of chemical neuroanatomy, pp 141-245. Amsterdam: Elsevier.

Paxinos G, Watson C (1986) The rat brain in stereotaxic coordinates, 2nd Edition. Sydney: Academic.

Peters A, Palay SL, Webster HDEF, eds (1991) The fine structure of the nervous system, neurons and their supporting cells. Oxford: Oxford UP.

Pettit HO, Ettenberg A, Bloom FE, Koob GF (1984) Destruction of dopamine in the nucleus accumbens selectively attenuates cocaine but not heroin self-administration in rats. Psychopharmacology (Berl) $84: 167-173$.

Rassnick S, Stinus L, Koob GF (1993) The effects of 6-hydroxydopamine lesions of the nucleus accumbens on oral self-administration of ethanol in the rat. Brain Res 623:16-24.

Raymond SA, Lettvin JY (1978) Aftereffects and nervous coding. Physiology and pathobiology of axons, pp 203-225. New York: Raven.

Reynolds E (1963) The use of lead citrate at high $\mathrm{pH}$ as an electronopaque stain in electron microcopy. J Cell Biol 17:208.

Risinger FO, Dickinson SD, Cunningham CL (1992) Haloperidol reduces ethanol-induced motor activity stimulation but not conditioned place preference. Psychopharmacology (Berl) 107:453-456.

Rocha BA, Fumagalli F, Gainetdinov RR, Jones SR, Ator R, Giros B, Miller GW, Caron MG (1998) Cocaine self-administration in dopamine-transporter knockout mice. Nature Neuroscience 1:132-137.

Sesack SR, Pickel VM (1992) Prefrontal cortical efferents in the rat synapse on unlabeled neuronal targets of catecholamine terminals in the nucleus accumbens septi and on dopamine neurons in the ventral tegmental area. J Comp Neurol 320:145-160.

Seutin V, Verbanck P, Massotte L, Dresse A (1990) Evidence for the presence of $N$-methyl-D-aspartate receptors in the ventral tegmental area of the rat: an electrophysiological in vitro study. Brain Res 514:147-150.

Shizgal P, Kiss I, Bielajew C (1982) Psychophysical and electrophysiological studies of the substrate for brain stimulation reward. The neural basis of feeding and reward, pp 419-429. Brunswick, ME: Haer Institute.

Simon H, Scatton B, Le Moal M (1979) Definitive disruption of spatial delayed alternation in rats after lesions in the ventral mesencephalic tegmentum. Neurosci Lett 15:319-324.

Simon H, Scatton B, Le Moal M (1980) Dopaminergic A10 neurones are involved in cognitive functions. Nature 286:150-151.

Spyraki C, Fibiger HC, Phillips HG (1982) Cocaine-induced place preference conditioning: lack of effects of neuroleptics and 6-hydroxydopamine lesions. Brain Res 253:195-203.

Steffensen SC, Raymond SA, Lee R-S, Henriksen SJ (1996) Ventral tegmental area non-dopamine neuronal activity and responsiveness to anesthesia. Soc Neurosci Abstr 22:1137.

Steketee JD, Kalivas PW (1991) Sensitization to psychostimulants and stress after injection of pertussis toxin into the A10 dopamine region. J Pharmacol Exp Ther 259:916-924.

Swanson LW (1982) The projections of the ventral tegmental area and adjacent regions: a combined fluorescent retrograde tracer and immunofluorescence study in the rat. Brain Res Bull 9:321-353.

Tepper JM, Martin LP, Anderson DR (1995) GABAa receptormediated inhibition of rat substantia nigra dopaminergic neurons by pars reticulata projection neurons. J Neurosci 15:3092-3103.

Thierry AM, Deniau JM, Feger J (1979) Effects of stimulation of the frontal cortex on identified output VMT cells in the rat. Neurosci Lett 15:103-107.

Thierry AM, Deniau JM, Herve D, Chevalier G (1980) Electrophysiological evidence for non-dopaminergic mesocortical and mesolimbic neurons in the rat brain. Brain Res 201:210-214.

Wang RY (1981a) Dopaminergic neurons in the rat ventral tegmental area. I. Identification and characterization. Brain Res Rev 3:123-140.

Wang RY (1981b) Dopaminergic neurons in the rat ventral tegmental area. II. Evidence for autoregulation. Brain Res Rev 3:141-151.

Wang T, French ED (1993) Electrophysiological evidence for the existence of NMDA and non-NMDA receptors on rat ventral tegmental dopamine neurons. Synapse 13:270-277.

Wang T, French ED (1995) NMDA, kainate, and AMPA depolarize nondopamine neurons in the rat ventral tegmentum. Brain Res Bull $36: 39-43$ 
Wilson CJ, Young SJ, Groves PM (1977) Statistical properties of neuronal spike trains in the substantia nigra: cell types and their interactions. Brain Res 136:243-260.

Wise RA (1980a) Action of drugs of abuse on brain reward systems. Pharmacol Biochem Behav 13:213-223.

Wise RA (1980b) The dopamine synapse and the notion of "pleasure centers" in the brain. Trends Neurosci 3:200.

Wise RA (1982) Intracranial self-stimulation: mapping against the lateral boundaries of the dopaminergic cells of the substantia nigra. Brain Res 213:190-194.

Wise RA (1996) Addictive drugs and brain stimulation reward. Annu Rev Neurosci 19:319-340.
Wise RA, Rompre P-P (1989) Brain dopamine and reward. Annu Rev Psychol 40:191.

Wise RA, Bauco P, Carlezon Jr WH, Trojniar W (1992) Selfstimulation and drug reward mechanisms. Ann NY Acad Sci 654:192-198.

Wolf ME (1998) The role of excitatory amino acids in behavioral sensitization to psychomotor stimulants. Prog Neurobiol 54:679-720.

Yeomans JS (1979) Absolute refractory periods of self-stimulation neurons. Physiol Behav 22:911-919.

Zhang J, Chiodo LA, Freeman AS (1993) Effects of phencyclidine, MK-801 and 1,3-di(2-tolyl) guanidine on non-dopaminergic midbrain neurons. Eur J Pharmacol 230:371-374. 